\title{
EL MUSEO DE ARTE INDÍGENA DE LA FUNDACIÓN ASUR. UNA EXPERIENCIA ESPECIAL
}

\author{
THE ASUR FOUNDATION'S MUSEUM OF INDIGENOUS ART. A SPECIAL \\ EXPERIENCE
}

\author{
Verónica Cereceda ${ }^{1}$
}

\begin{abstract}
El Museo de Arte Indígena de la Fundación ASUR en Sucre, exhibe principalmente textiles etnográficos de tres conjuntos étnicos del centro sur de Bolivia. Es pequeño y modesto pero su arquitectura y montaje, con su sencillez, le dan belleza y atractivo. Uno de sus valores es la presentación de prendas especiales, tanto por su estética como por la semántica que conllevan, que las destacan entre otros textiles andinos actuales del país. Podemos mencionar, también, el registro de los cambios que han experimentado sus diseños en los últimos veinticinco años, que permiten observar procesos de una nueva definición en la identidad de los grupos que los elaboran, que se van reflejando a través de las imágenes. Un valor especial está presente en su colección Tiwanaku, con textiles y objetos únicos en Bolivia. La exhibición va acompañada por textos antropológicos y numerosas fotografías, videos y música grabada proveniente de las mismas regiones de los textiles exhibidos.
\end{abstract}

Palabras claves: arte indígena, museografía especial, interculturalidad, textiles étnicos.

The Museum of Indigenous Art of the ASUR Foundation, in Sucre, mainly exhibits ethnographic textiles from three ethnic groups in South Central Bolivia. It is a small and modest museum, but its architecture and assembly, with their simplicity, give it beauty and attractiveness. One of its values is the display of special garments, as much for their aesthetics as for the involved semantics, which make them stand out from other present-day Andean textiles in the country. It is also worth mentioning the record of the transformations of the textile designs over the last twenty-five years, which allows us to observe the processes in the new definition of the identity of these groups through the images. Especially valuable is a Tiwanaku collection with textiles and unique objects in the country. The exhibition is accompanied by anthropological texts as well as numerous photographs, videos, and recorded music from the same regions of the exhibited textiles.

Key words: Indigenous art, special museography, interculturalism, ethnic textiles.

\section{El Museo de Arte Indígena}

Este museo se encuentra ubicado en una de las siete colinas que conforman la ciudad de Sucre, en Bolivia, junto al lugar más antiguo donde se fundó la ciudad, la plaza e iglesia de la Recoleta. La colina lleva el nombre sugestivo de Munay Pata (Altura del amor, en quechua). El edificio es muy sencillo, pequeño, con algunos muros de piedra y techos de teja que se integran bien a este barrio con ambiente colonial. El pasto y los árboles de la entrada, los cerros que se divisan al fondo y, especialmente, la arquitectura crean un espacio tranquilo y bello (Figura 1).

Este museo tiene una historia especial, ya que surge como consecuencia de un proyecto llamado "Programa de Renacimiento del Arte Indígena" que sostiene una relación viva y constante con la producción de textiles étnicos, como también, con la revitalización de danzas, música, ceremonias y otras tradiciones exhibidas en las salas, que le otorgan, en cierto modo, su sello y su peculiaridad.

\section{Brevemente: el Programa de Renacimiento del Arte Indígena}

Un pequeño proyecto -una experiencia piloto llevada adelante por tres antropólogos (Verónica Cereceda, Gabriel Martínez y Ramiro Molina)- se propuso, hace unos años, revitalizar el arte textil en grupos tradicionales del centro sur de Bolivia. Esta revitalización se planteaba como un punto de apoyo y de partida para estimular la valorización de la propia

\footnotetext{
${ }^{1}$ Directora del Museo de Arte Indígena de ASUR. Fundación para la Investigación Antropológica y el Etnodesarrollo. Calle Iturricha 314. Sucre, Bolivia. veronicacereceda@gmail.com
} 


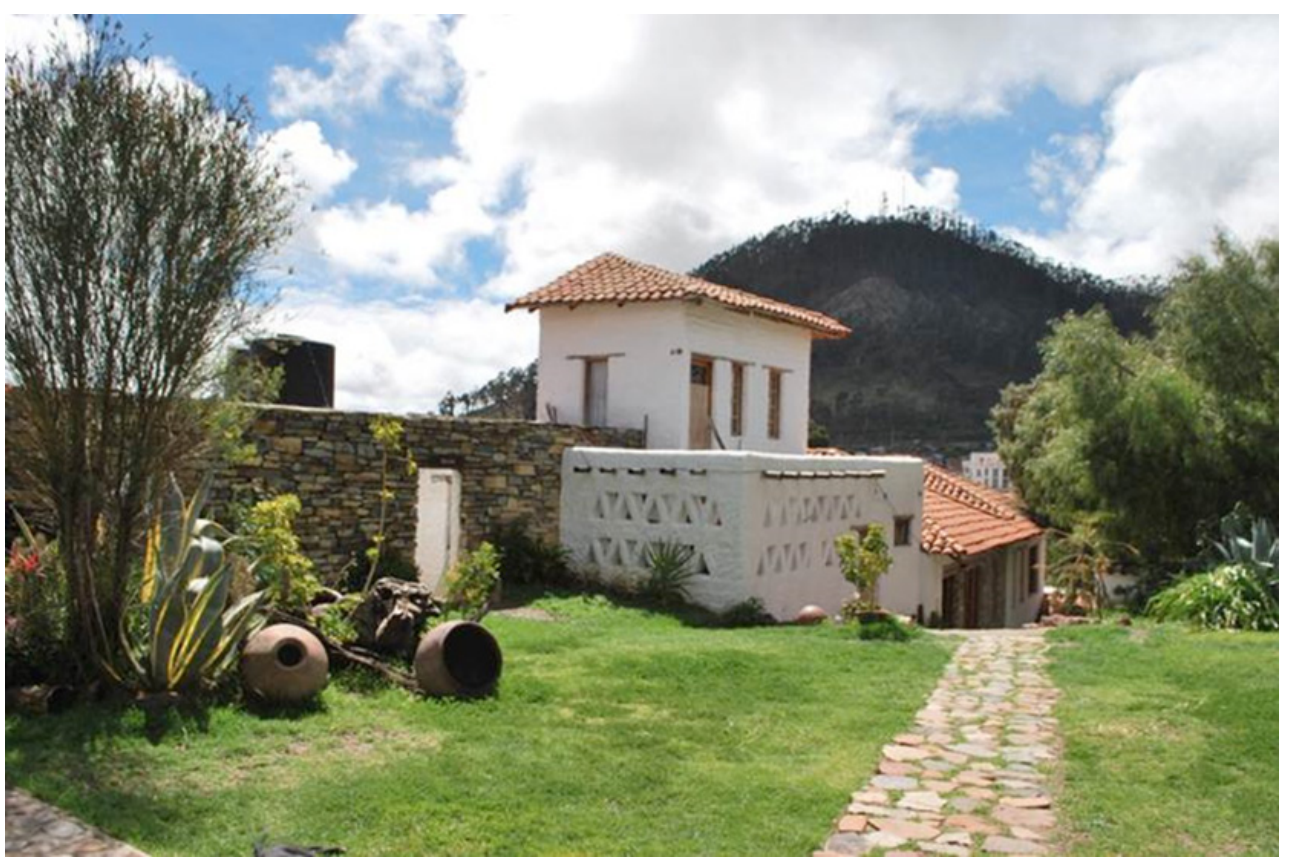

Figura 1. Entrada al Museo de Arte Indígena.

Entrance to the Indigenous Art Museum.

cultura y movilizar la energía colectiva ante los nuevos desafíos del mundo actual. Los grupos seleccionados fueron el jalq'a y el tarabuco-yampara ${ }^{2}$, cuyos textiles se encontraban ya, desde fines de los años 60, muy decaídos. Sin embargo, habían logrado un desarrollo excepcional a mediados del siglo pasado, y la expectativa era recuperar tanto los antiguos mensajes de sus diseños como sus altas calidades técnicas. Empezando por el área conocida como jalq'a y recorriendo numerosas comunidades, el proyecto fue proponiendo un desafío sencillo ¿qué comunidad querría organizarse para probar tejer tan finamente como antes? El estímulo era solo crear una pequeña colección que circulara entre las tejedoras de la región -para el recuerdo- y ver la posibilidad, aún remota, de comercializar textiles para generar recursos complementarios en una de las regiones más pobres de Bolivia.

Una pequeña comunidad, Irupampa, se auto seleccionó para iniciar la experiencia. Pero no fue sino después de una ceremonia llamada aysa, que los mallku o cerros tutelares "decidieron" tras largas discusiones a través de sus diferentes voces emitidas por el aysiri (oficiante)- que el proyecto "sería para bien", que el entusiasmo se apoderó de las tejedoras. Esta ritualidad inicial ha continuado vigente en el museo que surgió del proyecto.

Sancionado por esta manera tradicional de prever el futuro, el proceso iniciado en la comunidad de Irupampa fue seguido de cerca y con mucho interés por las comunidades cercanas. Tanto las "opiniones de los cerros" como los primeros textiles, muy interesantes y que provocaron el interés del público por adquirirlos dada su originalidad, atrajeron numerosas tejedoras de la región jalq'a y luego, de la cercana región tarabucoyampara. Así, lo que era un pequeño proyecto piloto se transformó en el Programa de Renacimiento del Arte Indígena, que llegó a trabajar con unas 25 comunidades y más de mil artesanos entre tejedoras y tejedores. Hoy, con los fuertes cambios que están ocurriendo en el área rural, se ha reducido a unos quince talleres productivos en los departamentos de Chuquisaca y Potosí.

Esta metodología de participación y de ritualidad ha continuado siendo el espíritu, tanto del Programa de Renacimiento del Arte Indígena como de su museo.

\section{Origen del museo}

El pronto surgimiento de una extraordinaria creatividad en los diseños de las prendas, que, aunque basados en la tradición, iban perfilando mucho más claramente un mensaje étnico, como el interés apasionado que nació entre las tejedoras por su trabajo, más una comercialización exitosa, hicieron surgir la necesidad de formar colecciones que guardando la memoria, registraran estos procesos.

Aunque el objetivo inicial del museo fue la formación de una exhibición permanente dirigida a visitantes campesinos, se ha convertido, también, en uno de los 
principales atractivos turísticos de Sucre, permitiendo el encuentro de los visitantes urbanos (extranjeros y nacionales) con la estética y el pensamiento indígenas del centro sur de Bolivia. Además, su puesta en marcha abrió otras potencialidades: la más importante, quizás, ser un lugar de comunicación entre áreas originarias distantes entre sí. El museo es también un espacio al que acuden tejedores de otros departamentos del país, que lo visitan para inspirarse y encontrar estímulo para realizar sus propias revitalizaciones culturales.

No contábamos, sin embargo, con los recursos necesarios para montarlo. Desde su inicio y hasta ahora, el Museo de Arte indígena ha tenido fuertes problemas de financiamiento. Estas restricciones se manifiestan, por ejemplo, en la iluminación que debería ser mucho más adecuada, en la ausencia de un control de la hidrometría y temperatura en sus ambientes o en la fragilidad de las instalaciones de conservación y fichaje de sus colecciones y objetos no exhibidos.

\section{Desafíos iniciales y algunas soluciones}

Al principio, el Museo de Arte Indígena estuvo por casi veinte años en la Casa de la Capellanía, edificio colonial del año 1623. Esta construcción de ambiente monacal, representó un fuerte reto museológico. Dos propósitos fundamentales nos guiaron: crear un ambiente acogedor para los visitantes venidos del campo, considerados sus protagonistas y sus espectadores principales, y despertar admiración y respeto por las poblaciones y culturas originarias del entorno de Sucre, en el público citadino, nacional y extranjero. Hace veinticinco años, luchar por este objetivo nos parecía una necesidad imperiosa.

Desde el comienzo fuimos instrumentando varios recursos para que las personas venidas del área rural no se sintieran intimidadas por el ambiente de un museo con sus objetos separados de su contexto y de su uso normal. Definimos así una estética museológica que intenta producir continuidad con los ambientes naturales y culturales de las comunidades. Este mismo principio ha sido conservado en la actual instalación de Munay Pata.

La entrada produce desde ya una sensación de campo, en medio de la ciudad, con su espacio de pastos, algunos árboles y los cerros al fondo cubiertos de verde, además de un caminito de piedra que lleva al museo. Las construcciones son rústicas y muy sencillas, con varios muros de piedra sin labrar y tradicionales techos de tejas.

Al interior, la presencia de maderas sin tratar, en tarimas, en algunas pocas vitrinas, puertas y vigas; o la caña hueca en instalaciones que evocan techos, igualmente, las paredes rugosas y blancas como si fuesen de cal, recuerdan -sin intentar en absoluto imitarla- una vivienda rural. A estas texturas y perfumes (de maderas y cañas) se suman la música y ambientes sonoros, grabados en las comunidades.

La semipenumbra de los focos dirigidos hacia las prendas más importantes y las luces muy discretas al interior de las vitrinas, aunada a la sobriedad del montaje, crean un ambiente especial: otra realidad que rompe, en los visitantes, las sensaciones urbanas (Figura 2).

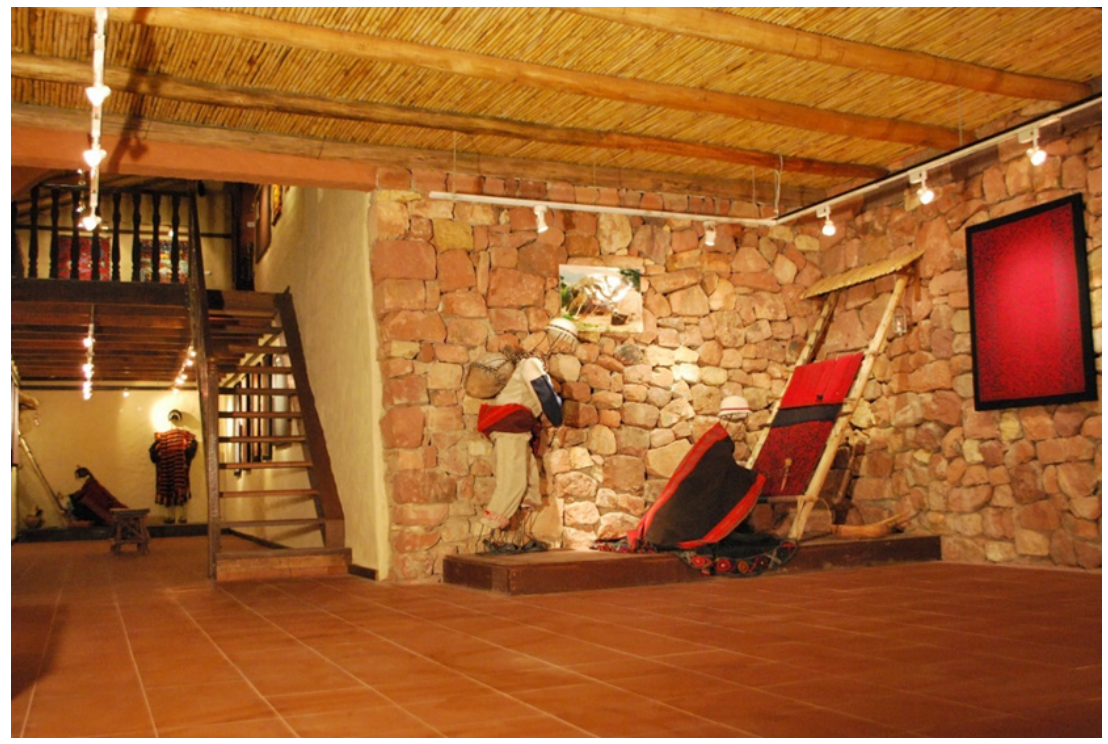

Figura 2. Una vista interna del museo.

An inside view of the Museum. 
Las siluetas de los maniquís también se integran al montaje sin distorsionarlo. Una de nuestras principales soluciones fue precisamente la invención de siluetas transparentes de hilos gruesos de metal, creadas ya en la instalación del primer local: no retratan a nadie en especial pero permiten exhibir el vestuario completo y las diferentes posturas que toman los personajes, según su actividad, produciendo una impresión de presencias humanas. Han resultado tan eficientes que hoy son un sello de la ciudad de Sucre y gran parte de las exposiciones y tiendas comerciales las reproducen.

La intención de promover el respeto y admiración hacia estas poblaciones se reflejó en el nombre: Museo de Arte Indígena. Sin desconocer lo ambiguo del término "arte" para un montaje antropológico, nos pareció el más adecuado para imponer, desde la entrada, cierta valoración por los objetos expuestos. En esos años y todavía ahora, los textiles étnicos eran vendidos como objetos folklóricos directamente sobre el suelo de las calles. Y si llegaban a exhibirse en alguna exposición local, prendas como ponchos, mantas tradicionales de las mujeres (liqlla) u otras, se mostraban siempre inclinadas o plegadas, imponiéndoles un carácter meramente decorativo. El museo desdobló los textiles y los expuso permitiendo ver su diseño completo y la originalidad estética de cada prenda. Los textos que los acompañan les agregan un valor adicional entregando una lectura antropológica de las imágenes.

\section{Las Exhibiciones}

De las once salas que se tenían en el Caserón de la Capellanía, en el nuevo local ha sido posible montar solo nueve. Cuatro de ellas están dedicadas a las colecciones de textiles etnográficos, incluyendo algunos más antiguos que se han podido recuperar. Constituyen uno de los temas principales del museo y están íntimamente vinculadas al Programa de Renacimiento del Arte Indígena. Otro aspecto no menos interesante de esta sección, son las transformaciones creativas en los diseños que se han ido manifestando en formas, contornos de motivos, estructura del espacio, colores y figuras (Cereceda 2010, 2016). Se trata de una pequeña historia, plástica e ideológica, de 1990 a 2016, ampliamente documentada en los objetos exhibidos. Este registro que abarca comunidades provenientes de grupos originarios del centro sur de Bolivia: Tinguipaya (Departamento de Potosí), Jalq'a y Tarabuco-Yampara (Departamento de Chuquisaca), asombra por la vigente vitalidad creativa de caseríos y pequeños pueblos que paradojalmente parecen estar abandonando sus tradiciones.

La quinta salita exhibe objetos cargados de ritualidad, algunos de los cuales siguen manteniendo sus poderes y son destinatarios de pequeñas ceremonias a pesar de estar en vitrinas. La sexta y séptima salas muestran una colección excepcional: objetos y textiles extraídos de un solo lugar, un contexto funerario de época Tiwanaku en una cueva, con materiales únicos en Bolivia.

En las salas etnográficas los maniquís llevan el vestuario completo de hombres o mujeres según la región a la que pertenecen. Una importancia especial tiene la exhibición de los aqsu, prenda principal del vestuario femenino, correspondiente hoy a un manto que cubre la espalda y va ajustado con una faja a la cintura. En los últimos tiempos esta prenda ha sufrido un impresionante desarrollo en sus diseños, constituyendo cada una un textil único de gran valor estético y semántico.

\section{Sala Tinguipaya}

Inmediatamente después de la recepción se ubica la Sala del ayllu Tinguipaya, gran organización tradicional conformada por un total de unos veinticinco mil pobladores. La muestra corresponde al sub ayllu Mañu que se sitúa en las altas punas del norte de Potosí. Mapas y fotografías, un pequeño techo que evoca el interior de una casa con un personaje y algunos objetos de la vida diaria, además del maniquí de una mujer tejiendo, acompañan a la exhibición textil.

Los diseños de estas poblaciones tienen un carácter más abstracto. Evocan "Gloria", el cielo, "lo de arriba" (araq pacha, en quechua), parte del universo ${ }^{3}$ con la que se identifican las poblaciones de puna. Dentro del Programa de Renacimiento del Arte Indígena, las tejedoras desarrollaron imágenes cautivadoras en este estilo no icónico, que se distingue por el uso de muchos colores vivos (Figura 3). Según los tinguipaya sus textiles se reconocen como los que "astawan k'anchan" es decir, "los que más iluminan". Estas luces radiantes son concebidas como propias de los espacios y entidades de "arriba", Gloria. Además, los diseños se estructuran en bandas que ordenan el espacio tejido con motivos repetitivos. Dicho orden es otra característica del mundo concebido como Gloria (Cereceda 2013).

Una de las técnicas de confección de estos textiles, es conocida como roscara (Cereceda 2013). No utilizada ni por los jalq'a ni los yampara, usa en cada urdimbre tres hilos de tonos distintos, permite ir obteniendo cambios de color al interior de las formas: un resultado hermoso y atractivo.

\section{Sala de Danzas y Música}

Aquí, el visitante debe desplazarse entre la presencia casi viva de numerosos maniquís vestidos para participar en ceremonias tanto de la región yampara como de la jalq'a. Completan el montaje los instrumentos musicales, un puesto de escucha donde es posible oír todas las músicas de estas áreas y un video en loop mostrando danzas y 


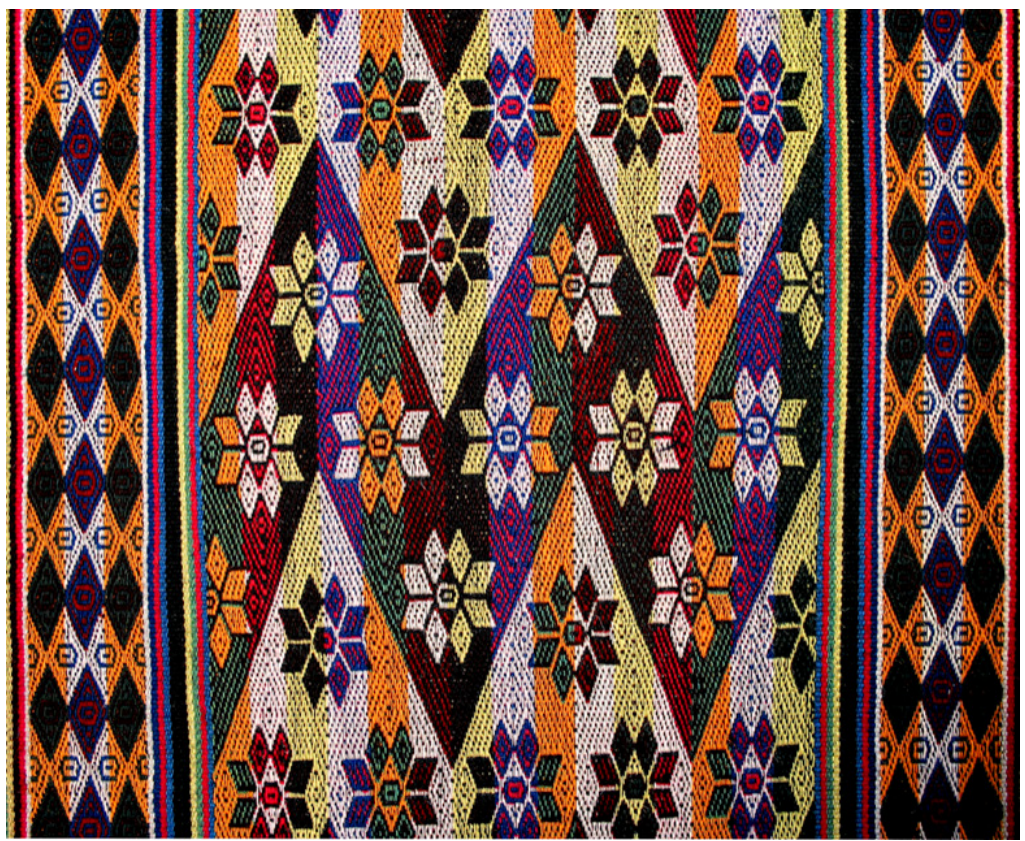

Figura 3. Detalle de un aqsu tinguipaya.

Detail of a Tinguipaya aqsu.

música en su contexto ritual. Los textos realizados por la etnomusicóloga Rosalía Martínez de largo trabajo en la zona (Martínez 2010, 2014), guían al espectador acercándolo al universo sonoro regional (Figura 4).

\section{Sala Jalq'a}

Este es un espacio más amplio donde se imponen la penumbra y la sencillez de la arquitectura. El

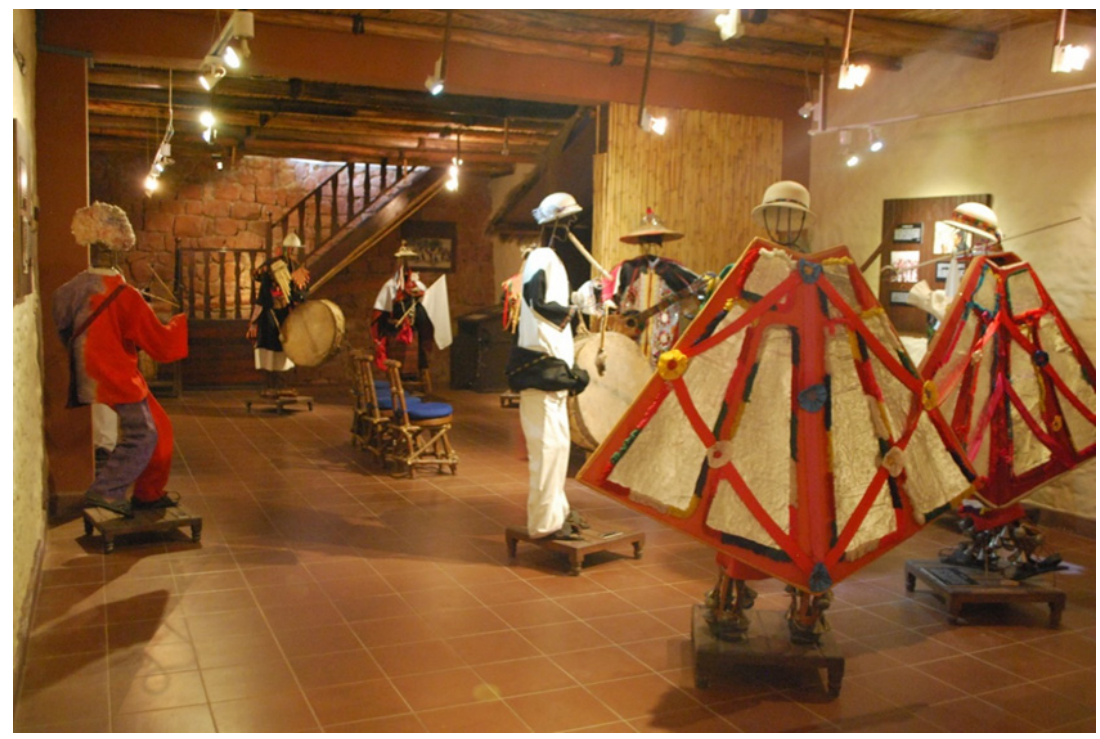

Figura 4. Vista de la Sala de Danzas y Música.

View of the Dances and Music Room. 
cromatismo de los textiles agrega su luminosidad propia. Los tonos utilizados en la elaboración de estas piezas niegan el contraste y son solamente dos, algunas pocas veces tres: un fondo negro, azul o verde muy oscuro, y un rojo o sus variantes fucsia o naranja para las figuras, también ensombrecidas. Los colores producen así uno de los efectos deseados por las tejedoras: la presencia de un mundo no accesible fácilmente a la mirada humana, muy diferente al de otros conocidos textiles andinos, tan nítidos en sus diseños.

A esta relación entre los tonos expuestos que, según sus creadoras, "deben encontrarse entre sî", se suman las formas sinuosas y los contornos a veces irradiantes de las figuras, creando voluntariamente una impresión de confusión, evocando el universo profundo, interior, sea de los cerros, las piedras o la tierra, llamado ukhu pacha y opuesto al cielo o "Gloria" (Cereceda 2018, 2016, 2010).

Las imágenes más recientes de estos aqsu, tejidas ya en el siglo XXI, imponen una necesaria atención para captarlas: muy abigarradas, con personajes no fáciles de identificar-demonios con distintas apariencias, almas de muertos, hermosos y extraños animales conocidos como khuru, todos pertenecientes a este mundo subterráneo-, cuya representación no tiene un punto de mira, ni centro o estructuras que permitan ubicarse en él.

Los textiles jalq'a son un emblema del Museo de Arte Indígena. Diríamos que es el museo quien ha dado a conocer la cultura jalq' $a$ al interior de Bolivia y a nivel internacional. No hay en el país ni en el extranjero otra colección de estos textiles tan completa, capaz de evidenciar las transformaciones en el imaginario y en el pensamiento de estas comunidades a lo largo de más de cien años. Como sabemos, los textiles se deshacen y destiñen con el uso, por lo que es muy difícil obtener ejemplares muy antiguos, pero el museo tiene la suerte de conservar dos aqsu de 1882 que permiten percibir los cambios estilísticos en las prendas (Figura 5). Además, otras piezas muestran diseños que son antecedentes más

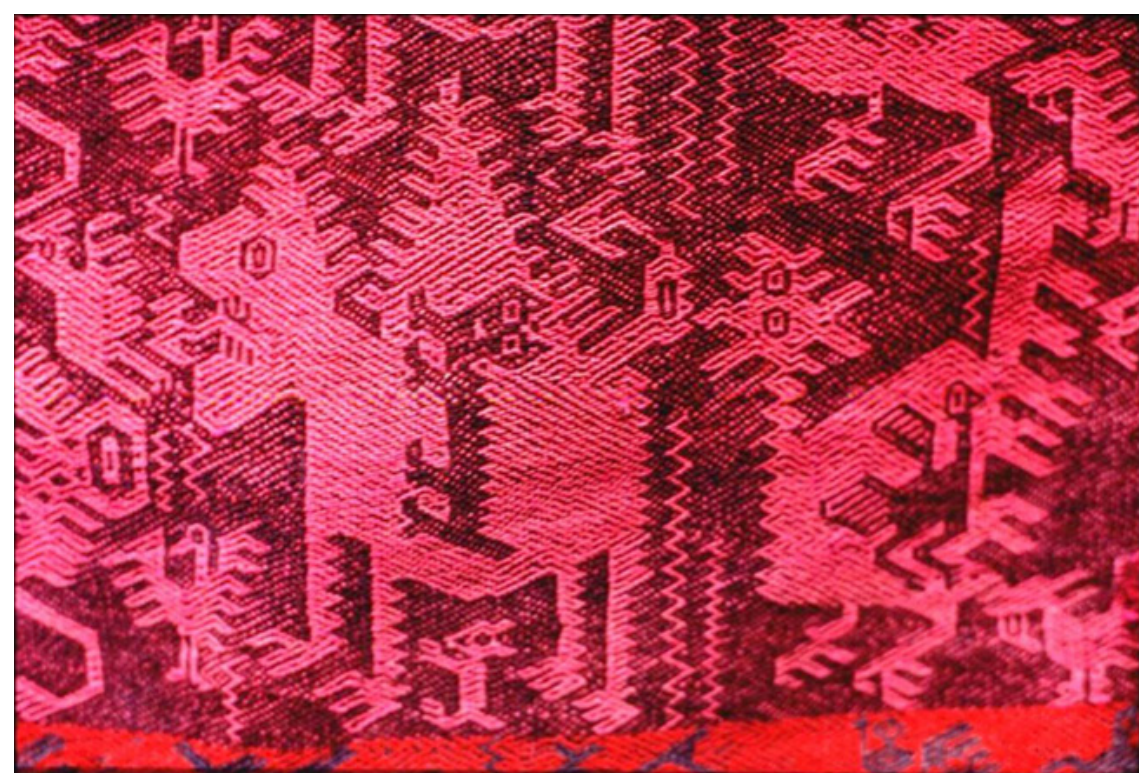

Figura 5. Detalle de un aqsu jalq'a antiguo, aproximadamente de los años sesenta. Personajes llamados khuru, imposibles en la realidad.

Detail of an ancient Jalq'a aqsu, ca. 1960s. Characters called khuru, impossible in reality.

inmediatos de lo que se teje hoy en día. Mostrar estos procesos nos parece tan importante como la exhibición misma de algunos aqsu realizados en los últimos años, bellos, especiales: demuestran la imaginación en constante movimiento de los pueblos indígenas en los entornos de Sucre (Figura 6).

\section{Espacio ritual}

Este es un espacio pequeño. Un cántaro conserva las cenizas de la ceremonia, llamada mesa, que se realizó para la apertura de esta segunda ubicación del museo; una vitrina exhibe platos ceremoniales con diversos contenidos: conjunto de hierbas, esencias odorantes, dulces decorados con diseños que llevan diferentes temas, que fueron utilizados por los oficiantes como ofrendas a los dioses tutelares, para que en la vida del museo "todo sea en buena hora". Entre otros objetos, se muestran algunas fajas cuyo diseño impide que los males ingresen a los infantes, así como piedras y manitos talladas utilizadas simbólicamente para que la materia prima, el hilado, dure y alcance. 


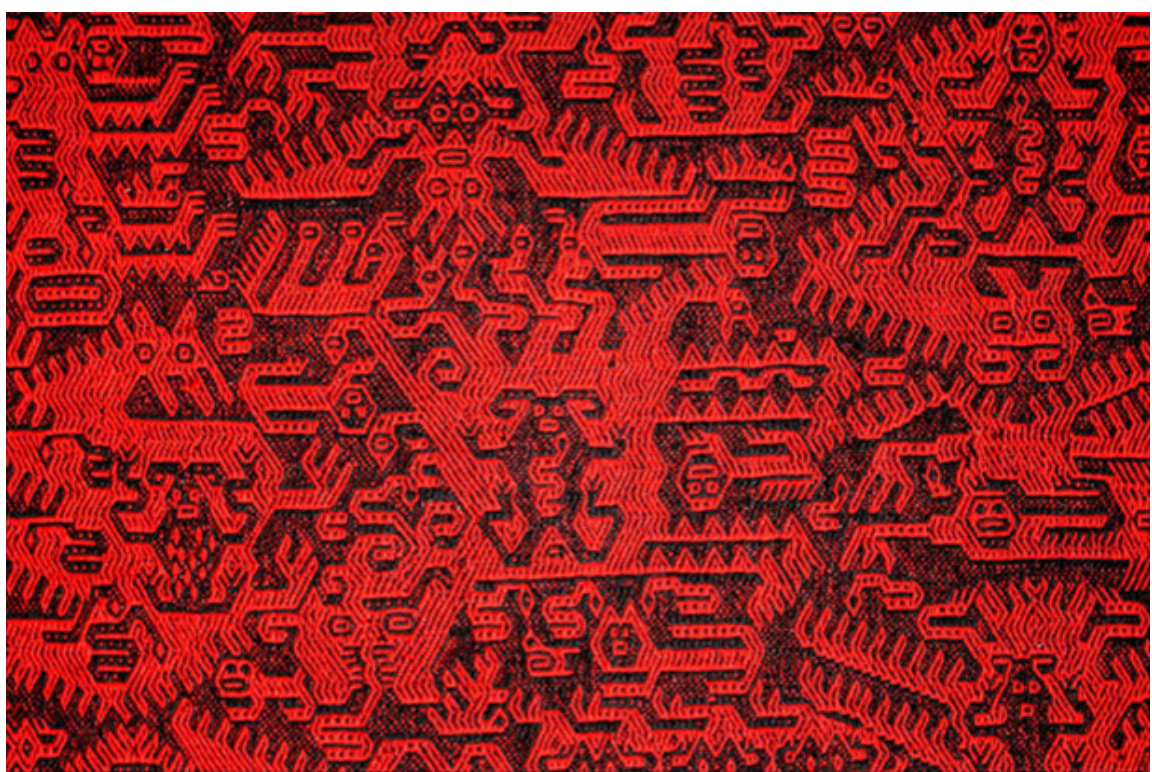

Figura 6. Detalle de un aqsu actual. El entrelazado de las figuras hace difícil su percepción individualizada, aunque están perfectamente tejidas de una en una.

Detail of a present-day aqsu. The interweaving of the figures makes it difficult to perceive them individually, although they are perfectly woven one at a time.

Una amplia vitrina contiene las vírgenes que favorecen el arte de tejer. Son piedras muy pequeñas que de diferentes maneras, han manifestado sus poderes. Una vez que esto ocurre, un sacerdote nativo (yatiri) les pregunta quienes son ¿Candelaria? ¿Guadalupe? ¿Otra virgen? Cuando ya se conoce su identidad, como son fácilmente transportables, se las viste y pinta y se les construye un retablo: una caja de madera con sus puertas decoradas y abiertas. En fechas programadas del año, sus dueños le hacen una ceremonia para que ayude a la prosperidad del ganado y de las tierras. En estas ocasiones las vírgenes reciben la visita de tejedoras con ofrendas, que les ruegan les den la maestría y la inspiración necesarias para realizar los mejores textiles (Figura 7).

Hoy estos retablos casi han desaparecido. Una familia que cambió su religión tradicional por otro culto, en el momento en que iba a quemar su retablo como si hubiese sido un objeto del demonio, recibió una oferta del museo y nos lo vendió. Dicho retablo se ha colocado en el centro de la vitrina acompañado por textiles en miniatura que elaboraban las mujeres mientras iban a visitarlo.

Años después de estar exhibido, la familia y otras personas de su comunidad regresaron a sus creencias más antiguas y quisieron recuperar la virgen para devolverla al campo y celebrar su cumpleaños. No les iba bien ni con la agricultura ni con el ganado. Como esto no era posible, en estos últimos tiempos le realizan su ceremonia al interior del museo mismo, llenándolo de humo y de los perfumes de las ofrendas incineradas.

\section{Sala Yampara-Tarabuco}

Esta sala exhibe textiles con imágenes muy diferentes. Su técnica combina hilos blancos de algodón con hilos de oveja teñidos en colores vivos. Los blancos siempre van al fondo, lo que permite destacar a las figuras no solamente por sus tonos sino por la materia prima, el hilo de oveja, creando un relieve que las hace sobresalir. El espacio del diseño está estructurado por bandas simétricas en espejo destacando un centro. La mirada -a diferencia de lo que ocurre con los textiles jalq'a, aparentemente tan difíciles de entender- capta fácilmente lo expuesto en su parte decorada. Se trata ahora del kay pacha, del mundo humano y la vida en la comunidad.

Las colecciones muestran los procesos de transformación de estas imágenes tejidas que han ido construyendo la etnicidad tarabuco-yampara, desde algunos aqsu de antes de la Reforma Agraria, en $1953^{4}$, hasta otros contemporáneos. Antiguamente las comunidades tejían diseños muy sencillos, apenas franjas con puntos coloreados. Según lo que manifiestan las tejedoras, sus madres y abuelas empezaron a tejer la técnica del pallay, que permite obtener dibujos complejos, solo después de esta reforma precedida por una revolución indígena. Uno de los encantos de estos 


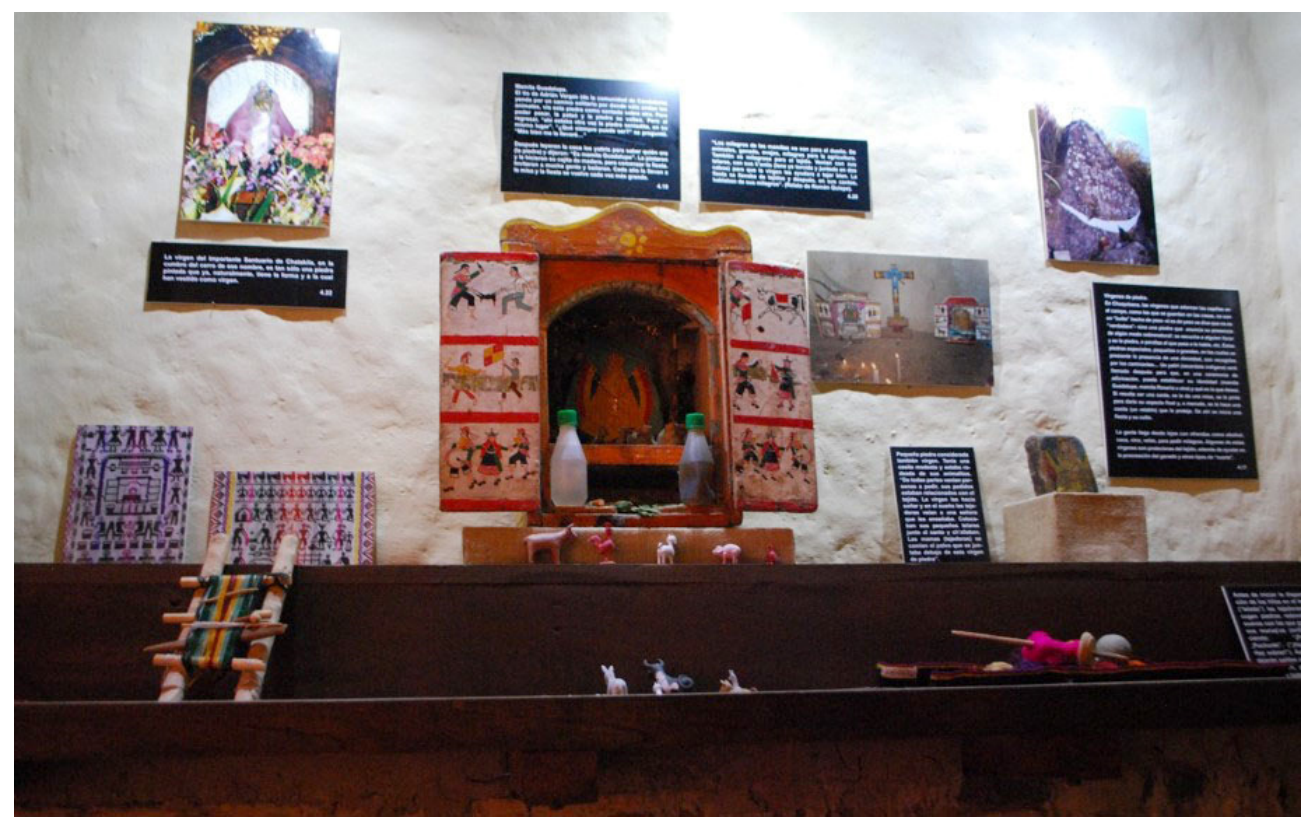

Figura 7. Vitrina de las vírgenes de Piedra.

Exhibit showcase of the Stone Virgins.

textiles reside en la finura del tejido y la miniatura de sus figuras tan perfectamente evocadas, con una belleza propia que le dan las sutiles degradaciones del color, inexistentes en los textiles jalq'a y tinguipaya.

Los textiles de los años 70 hasta los 90 del siglo pasado, eran conocidos por la presencia de hermosos caballos o llamas entre guardas abstractas. Luego fueron apareciendo otras representaciones de animales y algunas figuras muy estáticas, estandarizadas, de personas en hileras. Los diseños desde fines del siglo XX hasta ahora han desarrollado el tema de la vida en comunidad y sus grandes momentos: enamoramiento, matrimonio, fiestas, agricultura y ceremonias principales (Figuras 8 y 9 ).

La perspectiva en que se sitúan las tejedoras yampara es desde "este mundo" (kay pacha) la tierra. De modo que pueden observar el cielo. Arriba: el rectángulo oscuro representa la Vía Láctea con los personajes que la recorren. Abajo, es posible advertir una multitud de personas. Se trata de una celebración comunal en la cual los personajes tejidos toman diferentes posturas (técnicamente más difíciles de lograr) y realizan distintas acciones: Los podemos distinguir cortando leña, haciendo panes, preparando chicha, casándose en la iglesia o incluso cayendo al suelo en estado de ebriedad. Todo ello en miniatura, lo que le confiere parte de su encanto a estos textiles que constituyen verdaderos documentos etnográficos.

\section{Sala de Tapices}

Los aqsu hasta aquí exhibidos están tejidos en faz de urdimbre, aunque con diferentes técnicas. Pero subiendo unas gradas se entra en la sala de los tapices, cuyos diseños están elaborados en faz de tramas, y son el resultado de un proyecto dirigido a los hombres. En los primeros años del Programa de Renacimiento del Arte Indígena solo participaban las mujeres, pero viendo el éxito que ellas tenían y los recursos complementarios que aportaban, sin dejar sus tareas domésticas o agrícolas, los hombres también quisieron tejer. No era posible que compitieran con las técnicas tradicionales, dominadas por las mujeres. El Museo tomó la iniciativa de invitar dos expertas en tapices precolombinos, Paulina Brugnoli y Cecilia Rubilar que vinieron desde Chile para transmitir a grupos de varones seleccionados por las comunidades estas técnicas perdidas desde hace mucho tiempo en Bolivia. La sala exhibe el resultado de esta extraordinaria experiencia que se difundió posteriormente de manera autónoma en toda la zona (Figura 10).

Los tapices más impactantes surgieron de la región jalq'a: los hombres reconocieron en las figuras de tejidos andinos precolombinos a los khuru, esos extraños animales tejidos por las mujeres que pueblan el interior de la tierra, e intentaron hacerlos suyos, creando sus propios personajes. Esta sala 


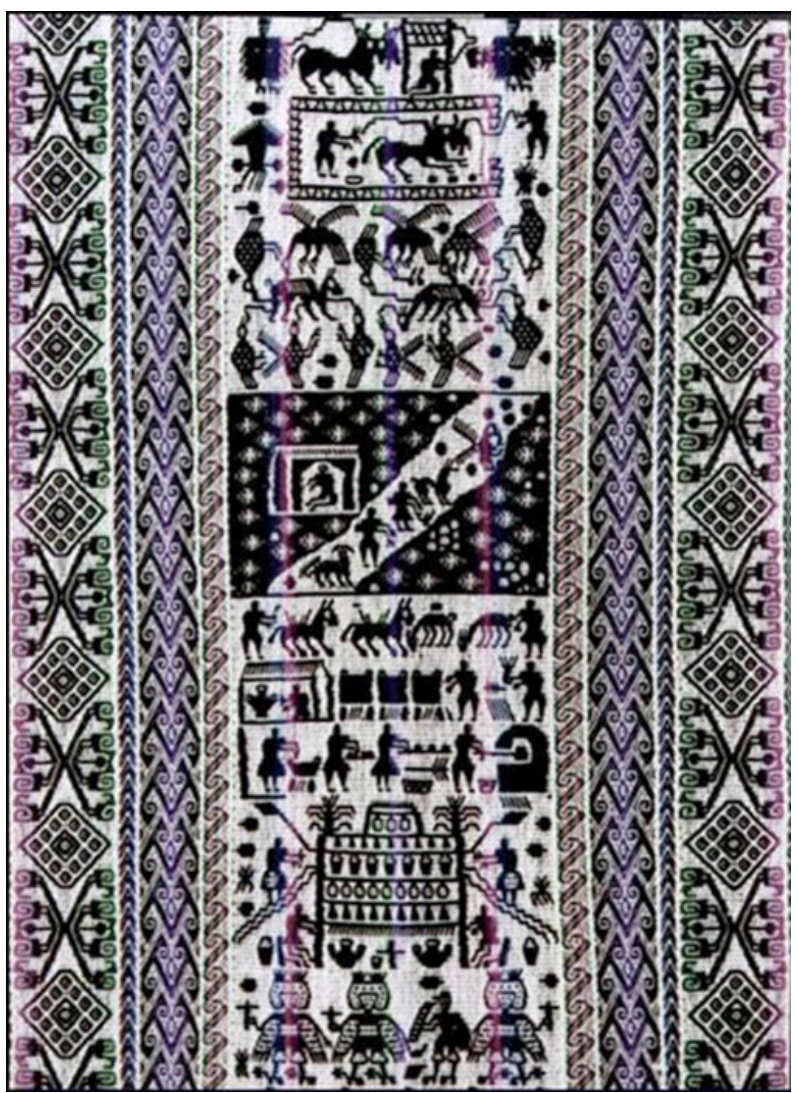

Figura 8. Detalles de escenas en un aqsu yampara.

Details of scenes in a Yampara aqsu.

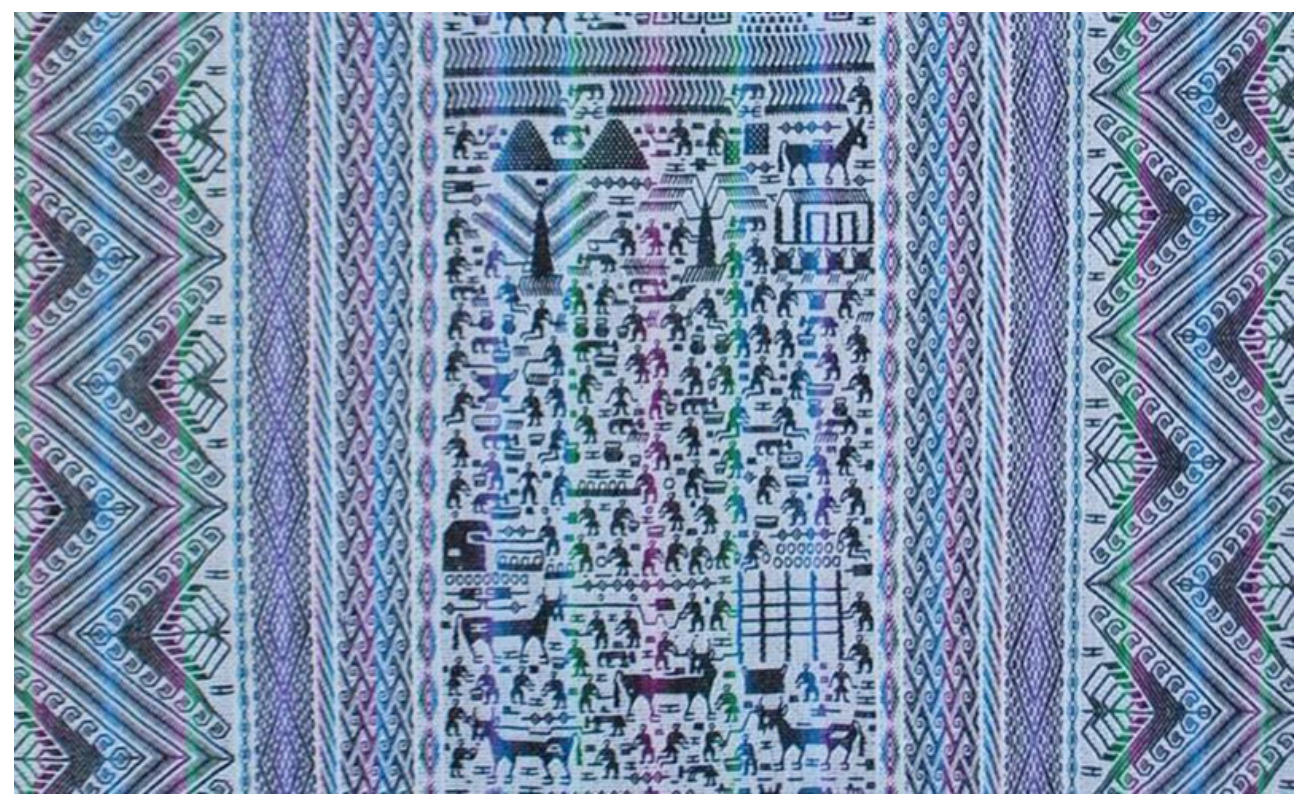

Figura 9. Otro detalle de una escena en un aqsu yampara.

Another detail of a scene in a Yampara aqsu. 

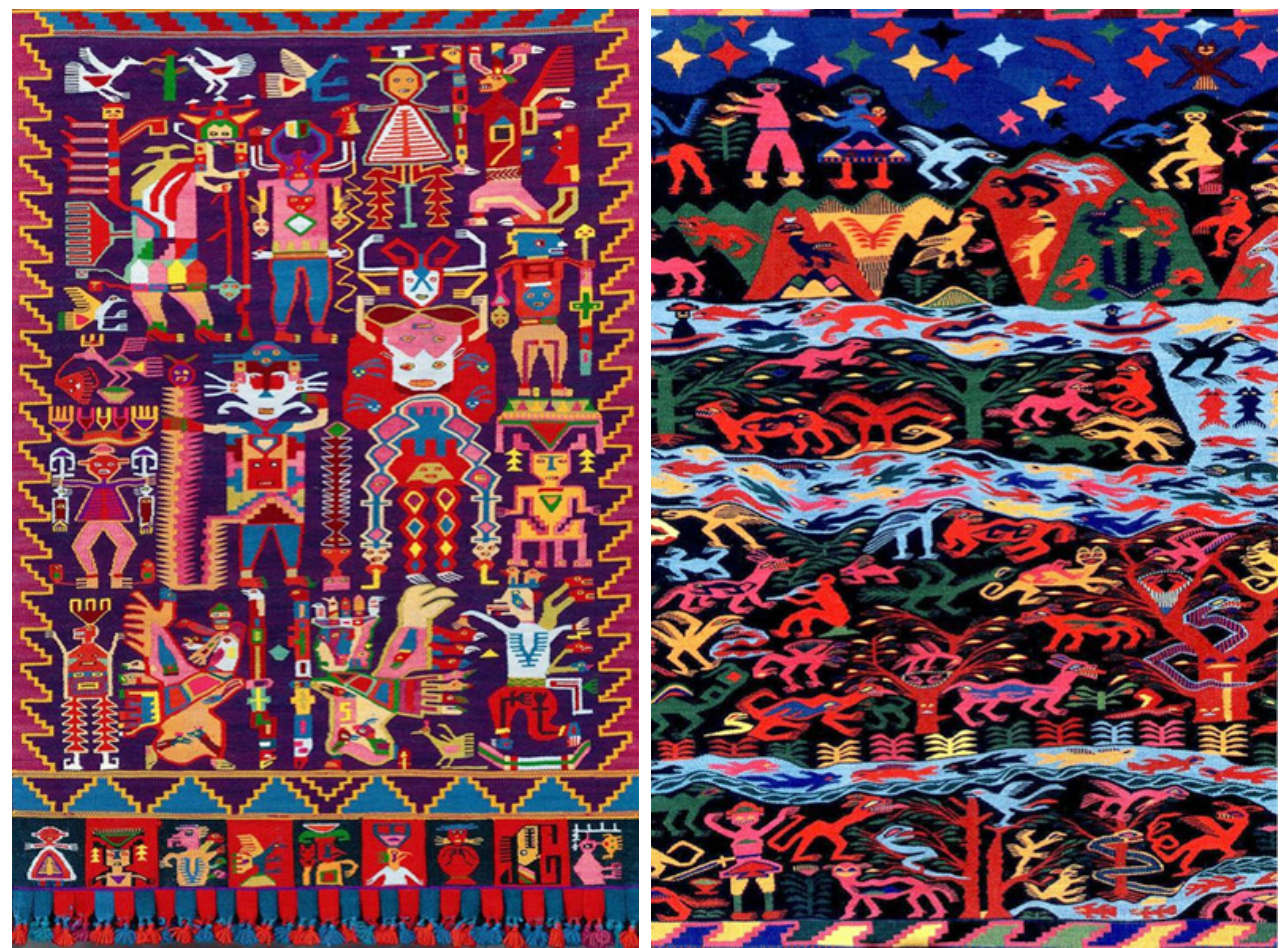

Figura 10. Tapices elaborados por hombres. (a) A la izquierda, el colorido y el khuru son de creación masculina. (b) A la derecha, la noche y los seres de lo profundo que aparecen con ella.

Tapestries made by men. (a) To the left, the colourful and the khuru are of male creation. (b) To the right, the night and the beings of the deep that appear with it.

muestra la extraordinaria capacidad que tuvieron los hombres para inventar complejas imágenes y dominar nuevas técnicas de telar.

\section{Sala Arqueológica}

Subiendo unas pocas gradas más se accede a algunas muestras de textiles y objetos prehispánicos. La colección principal está conformada por los materiales provenientes de un contexto funerario de época Tiwanaku denominado por los arqueólogos Pulacayo o Escaramayu (Agüero 2007; Letchman y Cruz 2010). El sitio se encuentra no muy lejos del Salar de Uyuni. Algo que no ocurre siempre, los objetos y textiles tienen procedencia conocida: una misma tumba ubicada en una cueva. En un inicio, se creyó que se trataba de alguna caravana proveniente del centro mismo de Tiwanaku, ubicado junto al lago Titicaca, en la cual algún señor importante había fallecido y fue depositado en la cueva, junto a ofrendas y cuatro acompañantes (Agüero 2007). El trabajo realizado por Letchman y Cruz (2010) demostró que se trataba de un gran emplazamiento no solo de tumbas, sino de industria y hornos de metales de la época.

A la entrada, se exhibe primero una vitrina con los típicos gorros tiwanaku tejidos en la técnica de anillado doble que permite volúmenes sin otro soporte. Aunque clásicos, tienen algunas peculiaridades no presentes en otras colecciones. Uno muy pequeño insinúa apenas sus cuatro puntas, como si estuvieran naciendo y su portador fuera muy joven. Otros dos llevan un acanalado que divide sus diseños en cuatro partes que, por lo general, en otros gorros son continuos. En seguida, una vitrina muestra dos cráneos y las numerosas y finas trenzas que les pertenecieron. Estos cráneos se han convertido para las actuales poblaciones indígenas en una presencia de sus "abuelos", recibiendo así ceremonias de comunidades cercanas cuando algo muy importante es urgentemente deseado. Mapas y textos informan sobre el sitio y el hallazgo.

Posteriormente, dos vitrinas -siempre con su estilo de techos de caña hueca y maderas sin tratar- exhiben las dos prendas principales. En la primera se ubica un unku, especie de camisa de los hombres en épocas precolombinas que fue tejido imitando el cuero de una alpaca (Figura 11). La técnica de sus mechones le da la apariencia de ser una piel animal, produciendo una extraña ambigüedad ya que es notoria su forma de vestuario. De este tipo de camisa masculina tiwanakota, hay muy pocos ejemplares en el mundo; es de tonos cafés y lleva como mangas conjuntos de hebras gruesas sin hilar, crespas (algo ya no corriente en las alpacas altiplánicas) y 
extraordinariamente largas. Sugiere haber sido no solo un excelente abrigo para las frías tierras cercanas al Salar de Uyuni, sino también, por su difícil confección, la vestimenta de algún personaje de alto rango.

En la segunda vitrina se exhibe, acompañado de otros objetos, el unku más importante tejido en técnica de tapiz. Los módulos de su diseño, repetidos en anchas franjas y alternando sus colores, muestran a un típico personaje de esas épocas conocido como el "sacrificador". De extraordinaria confección -sus hilos parecen cabellos por su finura-, es único en el mundo (Figura 12).

Varios objetos completan esta vitrina y las que siguen: inhaladores de hueso tallado, un brazalete de cobre, una pulsera de plata, varios tири o prendedores en miniatura con pequeñas figuras esculpidas, bolsitas de vejiga con polvos de colores, arcos y flechas, así como dos costales, entre otros más. Los costales llaman la atención ya que parece haber muy pocas de estas grandes bolsas tejidas para el transporte, en otros museos.

Subiendo unas gradas se encuentra una última salita, también Tiwanaku. Además de dos unku más sencillos que parecen haber sido de uso diario, destacan aquí vasos keru confeccionados con un tejido tan denso y fino de paja que puede contener líquidos. Un esqueleto de una tumba del sitio Pulacayo completa este ambiente.

\section{Algunos Logros}

Uno de los logros que nos parece fundamental, es que el museo ha logrado responder, simultáneamente, a necesidades culturales aparentemente muy disímiles: por una parte, ha creado un acercamiento de públicos urbanos a la estética indígena -públicos a la vez muy distintos entre sí, nacionales y extranjeros- por otra parte, se ha convertido en un verdadero registro activo de memoria para las comunidades. Este logro ha sido posible gracias al encuentro en la museografía, de un equilibrio, siempre frágil, entre la belleza de los objetos, la información etnográfica que los acompaña y la multisensorialidad de los ambientes.

Esta experiencia nos interroga sobre la naturaleza misma de lo que puede representar un espacio museal para las poblaciones concernidas. Hemos mencionado suficientemente el encuentro intercultural que encarna el museo y también su importancia de soporte para una memoria (étnica, estética, y técnica), pero aún más allá, los rituales que suelen realizarse en este lugar, nos llevan a la gran temática del estatus ontológico de ciertos objetos expuestos que conservan su agencia (agency) a pesar de encontrarse tan desplazados de sus contextos de origen.

Hay varios logros del museo que han creado un impacto regional: hemos citado la apropiación de la

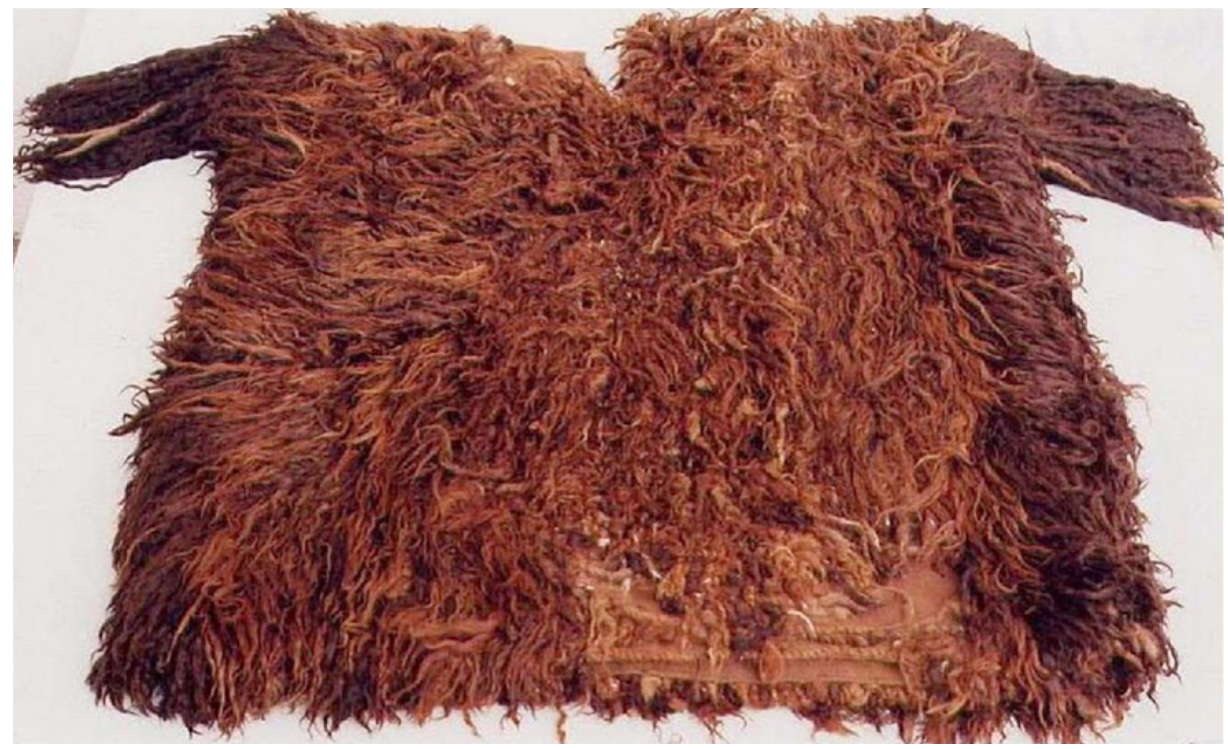

Figura 11. Unku Tiwanaku "peludo".

A "furry" Tiwanaku unku. 


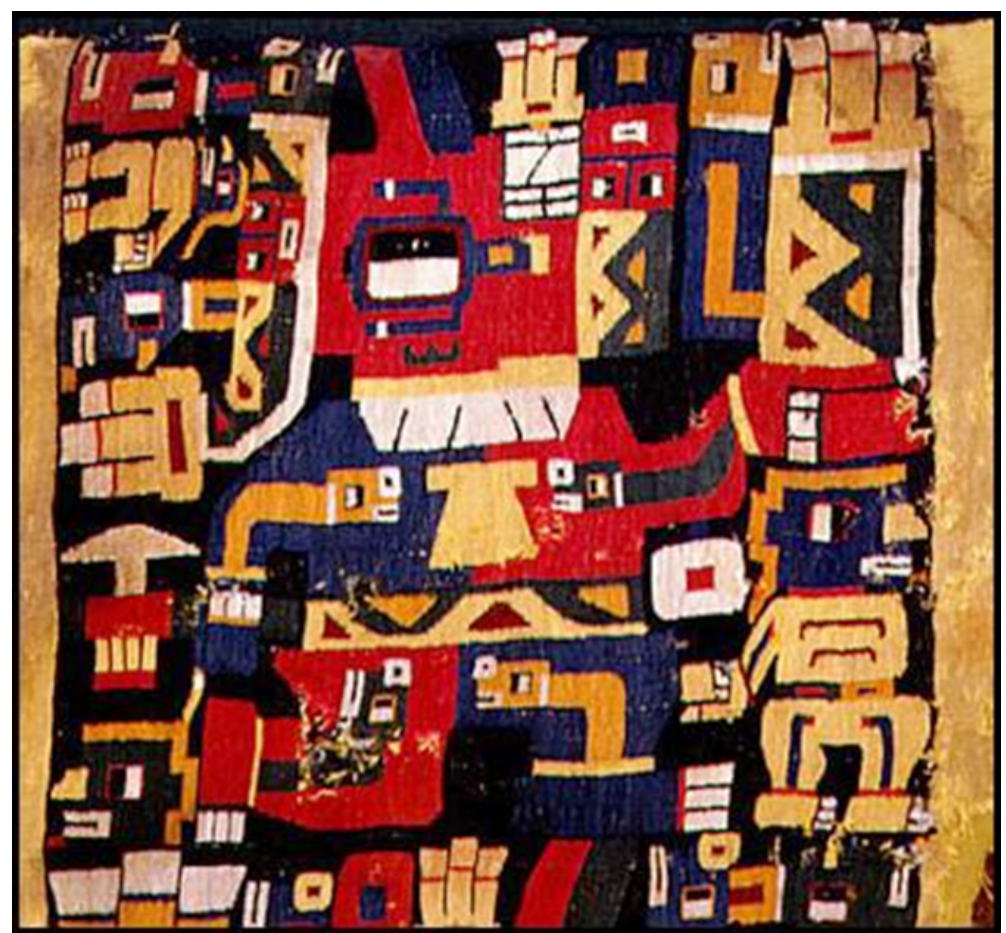

Figura 12. El personaje del unku tiwanaku en tapicería.

The Tiwanaku unku character in tapestry.

museografía por diferentes entidades locales, la difusión del conocimiento de las culturas indígenas en públicos muy amplios como los alumnados de escuelas y colegios, y el papel emblemático que estas culturas han alcanzado a nivel de la ciudad de Sucre. Sin embargo, un hecho particularmente interesante, es la difusión y el uso del imaginario textil jalq'a como un nuevo signo de la identidad de la región. Un ejemplo de esto, es que inesperadamente, los motivos jalq'a y textos del museo, han aparecido decorando un gran muro a la entrada del nuevo aeropuerto de la ciudad de Sucre.

Todos estos logros abren un camino con numerosas perspectivas. No podemos, sin embargo, dejar de mencionar que, al día de hoy, por ausencia de los recursos adecuados, el futuro del Museo de Arte Indígena está lejos de estar asegurado.

\section{Referencias Citadas}

Agüero, C. 2007. Los textiles de Pulacayo y las relaciones entre Tiwanaku y San Pedro de Atacama. Boletín del Museo Chileno de Arte Precolombino12 (1):85-98.

Bouysse-Cassagne, T. y O. Harris 1988. Pacha, en torno al pensamiento Aymara. En Raíces de América. El Mundo Aymara, editado por X. Albó, pp. 217-281. Alianza América, UNESCO.

Bouysse-Cassagne, T., O. Harris, T. Platt y V. Cereceda 1987. Tres Reflexiones sobre el Pensamiento Andino. HISBOL, La Paz.

Cereceda, V. 2006. Diseños de los Textiles T’inkipaya (Ayllu Mañu). ASUR, Sucre.

Cereceda, V. 2010. Demonios, barroco y diseños textiles. En Entre Cielo e Infiernos. Memoria del V Encuentro Internacional Sobre Barroco, pp. 259-270. Fundación Visión Cultural, La Paz.

Cereceda, V. 2016. En torno al supay andino. El aporte de lo visual a su interpretación. En Wak'as, Diablos y Muertos. Alteridades Significantes en el Mundo Andino, editado por L. Bugallo y M. Vilca, pp. 232-265. Universidad Mayor de Jujuy, EDIUM, IFEA, Jujuy.
Cereceda, V. 2019. Imágenes tejidas del ukhu pacha: inquietudes planteadas a los etnohistoriadores y arqueólogos, desde la etnología. En Interpretando Huellas. Arqueología, Etnohistoria y Etnografía de los Andes y sus Tierras Bajas, editado por M.A. Muñoz, pp. 501-517. Kipus, Cochabamba.

Cereceda, V., S. Porcel Gira, R. Quispe y B. Coronado 2013. Diseños en Aqsus Tarabuco-Yampara. ASUR, Sucre.

Estenssoro, J.C. 2003. Del Paganismo a la Santidad: La Incorporación de los Indios del Perú al Catolicismo, 1532-1750. IFEA, Lima.

Letchman, H. y P. Cruz 2010. Procesamiento de metales durante el Horizonte Medio en el altiplano surandino (Escaramayu, Pulacayo, Potosí, Bolivia). Boletín del Museo Chileno de Arte Precolombino 15 (2):9-27.

Martínez, R. 2010. La música y el Tata Pujllay. Carnaval entre los Tarabuco (Bolivia). En Diablos Tentadores y Pinkillos Embriagadores, editado por A. Gérard, pp. 143-181. Plural, Universidad Autónoma Tomás Frías, La Paz.

Martínez, R. 2014. Músicas, movimientos, colores en la fiesta andina. Ejemplos bolivianos. Anthropologica XXXII (33):87-110. 


\section{Notas}

${ }^{1}$ La unidad poblacional que se reconoce bajo el etnónimo jalq'a está formada por un conjunto de comunidades originarias que se encuentran repartidas al oeste y al norte de la ciudad de Sucre.

${ }^{2}$ El término tarabuco-yampara designa comunidades originarias que conforman hoy una unidad cultural. Estas comunidades no se auto-reconocen con un etnónimo común y eran usualmente llamados en la región "tarabucos". Actualmente, está emergiendo una auto-designación, "yampara", que los identifica con uno de los grandes grupos étnicos, antepasados principales de las poblaciónes actuales. Como en la literatura científica se los ha nombrado usualmente "tarabuco" y aún el término "yampara" no ha sido integrado por el conjunto de las comunidades, hemos elegido aquí utilizar la denominación "tarabuco-yampara".

${ }^{3}$ Sobre la concepción andina del universo y su división tripartita entre araq pacha, el "mundo de arriba", "del exterior", ukhu pacha, "lo de abajo", "del interior", y kay pacha, "lo de aquí", "este mundo", existe una abundante literatura antropológica. Ver p.ej., Harris y BouysseCassagne (1988), Estenssoro (2003), Cereceda (2016).

${ }^{4}$ Nos referimos a esta reforma porque trajo una convulsión política, social y económica en las poblaciones indígenas regionales, que al parecer impulsa también redifiniciones en las etnicidades expresadas por los textiles. 
